\title{
Factors associated with psychic symptomatology in diabetics during the COVID- 19 pandemic
}

Gustavo Fonseca de Albuquerque Souza 1

iD https://orcid.org/0000-0002-1794-701X

Gabriella de Almeida Figueredo Praciano 2

(iD) https://orcid.org/0000-0002-9746-8536

Otávio da Cunha Ferreira Neto 3

D https://orcid.org/0000-0003-0517-0212

Maria Carolina Paiva 4

(iD) https://orcid.org/0000-0001-9065-8030

Renata Patrícia Freitas Soares de Jesus 5

(iD) https://orcid.org/0000-0002-7106-2554
Ana Lorena Nascimento Cordeiro 6

iD https://orcid.org/0000-0001-6227-4937

Gabriela Albuquerque Souza 7

(iD) https://orcid.org/0000-0002-3631-6782

José Roberto Silva Junior 8

https://orcid.org/0000-0003-3843-005X

Alex Sandro Rolland Souza 9

(iD) https://orcid.org/0000-0001-7039-2052

1-5,7,9 Universidade Católica de Pernambuco. Rua do Príncipe, 526. Boa Vista. Recife, PE, Brasil. CEP: 50.050-900. E-mail: alexrolland@uol.com.br 6,8 Faculdade Pernambucana de Saúde. Recife, PE, Brasil.

\section{Abstract}

Objectives: to determine the frequency and factors associated with severe / extreme signs and symptoms of stress, anxiety and depression in diabetic patients during the COVID-19 pandemic.

Methods: cross-sectional study conducted in April / May 2020, which included 162 individuals with diabetes mellitus and over 18 years old. An online questionnaire was applied on social networks, composed of biological, sociodemographic, clinical characteristics and the Stress, Anxiety and Depression Scale (DASS-21). For statistical analysis, a multivariate logistic regression model was applied with a $5 \%$ significance level.

Results: frequency of $37.7 \%, 43.3 \%$ and $45.1 \%$ were found for some symptom of stress, anxiety and depression, respectively. The factors associated with sign and symptoms of severe / extreme psychic disorders were: not having religion (stress, anxiety and depression); be at graduation (stress and anxiety); history of anxiety and depression (anxiety and depression); not practicing or decreasing physical exercises and starting, increased or continue taking sleeping medications (stress); history of contact with a suspected case of COVID-19, absence or decreased leisure (anxiety); female gender, absence of a partner, decreased family income and work or study (depression).

Conclusion: the frequency of psychological disorders was higher than described in the literature on diabetic patients, being associated with biological, sociodemographic, clinical factors and aspects related to COVID-19 during the pandemic

Key words Anxiety, New coronavirus (2019-nCoV), Depression, Diabetes mellitus, Psychological stress

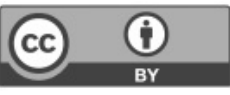




\section{Introduction}

Diabetes Mellitus (DM) is a disease characterized by high blood glucose levels resulting from pathogenic mechanisms ranging from complex genetic interactions to environmental factors and lifestyle habits, with central pathophysiological basis changes in pancreatic beta cells and insulin hormone functionality. ${ }^{1}$ According to the International Diabetes Federation (IDF), this disease affects approximately 463 million people worldwide, Brazil is the country with the 4th highest prevalence in the world. ${ }^{2}$ It is also evident that these patients are subject to lower expectations and quality of life, given the systemic repercussions such as cardiovascular diseases, retinopathies, neuropathies, nephropathies, infertility and psychiatric disorders 3 that may arise from this disease.

High morbidity and mortality, economic loss and stressful routine are frequent situations in patients with chronic diseases, such as DM and hypertension, which are commonly associated with the onset of mental disorders. 4 The relation between diabetes and psychiatric illnesses has been widely addressed, 3,5 it is believed that continuous care and diseases result from diabetes, such as routine monitoring of the blood glucose levels, daily insulin injections, diets and hospitalizations, contribute to emotional instability and the onset of psychopathologies. 3

Studies show that depressive disorders in diabetics correspond to twice the prevalence in nondiabetics, and that there is an average risk of $48 \%$ of diabetic patients developing anxiety, suggesting the existence of a bidirectional relationship between these diseases.5,6 Despite this and the existence of appropriate screening tests, more than half of the diabetics are not diagnosed for psychic symptomatology and do not receive adequate treatment, which contributes to worsening glycemic control. 4

Under these circumstances, the current situation of the severe acute respiratory syndrome coronavirus-2 (SARS-CoV-2) pandemic, which has been named COVID-19, represents a major global public health crisis, resulting in economic and social deficits. ${ }^{7}$ In addition to these impacts, directly caused by the disease, a high prevalence of psychic disorders during social distancing is being described, a measure recommended as a form of prevention for the entire population, especially for groups at high risk of mortality among diabetics. ${ }^{7}$

The marked severity and mortality of COVID-19 in patients with previous comorbidities, such as MD, associated with restrictive measures, such as social distancing, and the anxiety resulting from the fear of being infected create a stressful scenario, contributing to the association between diabetes and mental disorders. ${ }^{8}$ Thus, the present study sought to identify the frequency of psychic signs and symptoms in diabetics, as well as to analyze the associated factors, during the period of social distancing.

\section{Methods}

This is a cross-sectional study conducted between the months of April and May 2020 by researchers at the Universidade Católica de Pernambuco (UNICAP), located in Recife, Pernambuco. The sample was composed by natural or naturalized Brazilians, residents in Brazil and bearer of DM, being excluded those under 18 years old and those who did not fill out the form completely and correctly.

The sample size was calculated using the Staltcalc program of Epiinfo 7.2.4.0 (Centers for Disease Control and Prevention - CDC, United States of America - USA, Atlanta, DC). For a confidence level of $99 \%$, an acceptable margin of error of $10 \%$ and a frequency of $48 \%$ anxiety in diabetic patients, 5,6 160 patients would be required, which was increased to 180 predicting eventual losses.

For data collection, an online electronic form was developed using the Google Forms platform, through which an individual questionnaire composed of questions related to the objective of the survey. This instrument was previously tested and coded through a pilot study. The form was freely available on social network profiles such as Whatsapp, Instagram, Facebook, as well as forwarded by e-mail. The population was encouraged to participate as co-advertiser of the survey as they could forward the form to their peers, using the "snowball" sample methodology. 9 The survey form was available between April 24 and May 3, 2020.

The independent variables were grouped into biological, sociodemographic, life habits and clinical characteristics, which were dichotomized by investigating information on sex (male and female); age ( $<44$ years and $>44$ years); race/color (white and non-white); schooling (undergraduate, post graduate); religion (yes and no); work in the health area (yes and no); monthly income during the pandemic (remained the same/increased and decreased); has a partner (yes and no); have children (yes and no); history of anxiety and/or depression (yes and no); bearer of cardiovascular diseases (yes and no); practice of physical exercises, leisure activities, consume of alcoholic beverages, remote work/study and use of medication to sleep during the pandemic period 
(started/ increased/sustained and decreased/did not use); performed social distancing (yes and no); presented symptoms of COVID-19 (yes and no); and had contact with suspected cases and/or confirmed by COVID-19 (yes and no).

The dependent variables were composed by the presence of signs and symptoms for stress, anxiety and depression, evaluated through the application of the Stress, Anxiety and Depression Scale (DASS21). ${ }^{10}$ In DASS-21, the participants indicated the degree to which they experienced each of the symptoms described in the items during the last week (previous week) on a Likert type scale of four points between zero (does not apply to me) and three (applies very much to me or most of the time). The scores for stress, anxiety and depression were determined by summing the scores of the 21 items on the scale. For each subdimension assessed, the scale provides three scores, which are determined by the sum of the results of the seven items, being the minimum zero and maximum 21 points. The highest scores correspond to the most negative affective states. Thus, the stress subscale has no signs and/or symptoms (0-14), mild (15-18), moderate (19-25), severe (26-33) and extreme (>33). The subscale of anxiety has no signs and/or symptoms (0-7), mild (8$9)$, moderate (10-14), severe (15-19) and extreme $(>19)$. The depression subscale has absence of signs and/or symptoms (0-9), mild (10-13), moderate (14$20)$, severe (21-27) and extreme (>27). 10

The statistical analysis was performed by Epiinfo 7.2.4.0 software (CDC, USA, Atlanta, DC). The numerical variables were expressed in mean and standard deviation and the categorical ones in frequency distribution and absolute percentages. Analysis was performed to test the association of dependent and independent variables in the studied population, using the chi-square test, and the strength of this association was calculated by the prevalence ratio and its $95 \%$ confidence interval (CI95\%).

Then a multivariate logistic regression analysis was performed, with the initial model being composed of the explanatory variables that presented significance of $p<0.20$ in the univariate analysis, calculating the initial odds ratio (OR) and its CI95\%. For the final model, the variables with a significance level lower than 0.05 remained, the adjusted OR and its CI95\% are calculated.

The data collection was carried out respecting the principles of the Resolution 466/12 and was initiated after approval of the project by the Committee on Ethics in Research in Human Beings of the Universidade Católica de Pernambuco (UNICAP), under the number of CAAE - 30623020.1.0000.5206 and the document number $3,988,875$ on April 24, 2020, participants were included after agreeing and signing the Informed Consent Form in a virtual way.

\section{Results}

180 responses were obtained from patients with diabetes mellitus, of which 10 were excluded because they were doubled and eight by the participants that were $<18$ years old, therefore, leaving, 162 of the responses for analysis.

A mean age of $42.5 \pm 15.4$ years was identified to characterize the sample. Female $(69.8 \%)$, white $(58.0 \%)$, religious $(79.6 \%)$ and has a partner $(54.3 \%)$ individuals prevailed; $50.0 \%$ were health professionals. As for a history of diseases, $53.7 \%$ were bearers of cardiovascular disease and $41.4 \%$ had history of anxiety and depression. In relation to the consequence of the pandemic in these individuals' lives, $43.2 \%$ had their monthly family income decreased, $40.1 \%$ and $38.3 \%$ started/ increased/ maintained the consumption of alcoholic beverages and the use of sleeping medications, respectively.

As for the interpretation of the DASS-21 scale, the frequency of signs and/or symptoms for stress was $37.7 \%$, of which $10.5 \%$ were severe and $6.2 \%$ extreme. For the anxiety subscale, $43.2 \%$ presented signs and/or symptoms, being $19.1 \%$ moderate and $11.7 \%$ extreme. While for depression, $45.1 \%$ reported signs and/or symptoms, $6.2 \%$ being severe and $14.2 \%$ extreme (Table 1 ).

After the multivariate analysis remained associated with signs and symptoms of severe/extreme stress, in the final model, no religion $(\mathrm{OR}=5.7$; CI95\% $=2.06-15.78 ; p<0.001)$, undergraduated $(\mathrm{OR}=4.5$; $\mathrm{CI} 95 \%=1.36-14.60) ; p=0.01)$, the absence or decrease of physical exercises $(\mathrm{OR}=3.3$; CI95\% $=1.14-9.83 ; \mathrm{p}=0.03)$ and maintained/initiated or increased use of medication to sleep $(\mathrm{OR}=3.5$; C195\%=1.34-9.17; $p=0.01$ ) (Table 2).

They remained associated with the risk of signs and symptoms for severe/extreme anxiety: history of anxiety and/or depression $(\mathrm{OR}=8.6$; CI95\% $=2.54$ 29.32; $\quad p<0.001)$, undergraduated $(\mathrm{OR}=5.6$; $\mathrm{CI} 95 \%=1.44-22.00 ; \mathrm{p}=0.01)$, not having a religion $(\mathrm{OR}=8.1 ; \mathrm{CI} 95 \%=2.53-25.72) ; p<0.001)$, have had a history of contact with someone suspected for COVID-19 (OR=3.7; CI95\%=1.13-12.21; $p=0.03)$ and the absence or decrease of leisure practices during the pandemic $(\mathrm{OR}=16.9 ; \mathrm{CI} 95 \%=3.36-85.15$; $p<0.001$ ) (Table 3).

Finally, they remained associated with the risk of developing signs and symptoms for severe/extreme 
depression: female sex $(\mathrm{OR}=2.5 ; \mathrm{CI} 95 \%=1.33-4.72$; $p=0.004)$, absence of partner $(\mathrm{OR}=4.1$; CI95\% $=2.34$ $7.13 ; p<0.001)$, no religion $(\mathrm{OR}=2.2 ; \mathrm{CI} 95 \%=1.34$ $3.54 ; \mathrm{p}=0.002)$, history of anxiety and/or depression $(\mathrm{OR}=2.6 ; \mathrm{CI} 95 \%=1.64-4.14 ; p<0.001)$, reduced monthly income during the pandemic period $(\mathrm{OR}=$ $1.9 ;$ CI95\% $=1.18-3.11 ; p=0.008)$, and reduced work or remote study $(\mathrm{OR}=1.9 ; \mathrm{CI95 \%}=1.18-3.11$; $p=0.008$ ) (Table 4).

Table 1

Frequency of signs and symptoms of stress, anxiety and depression, according to the severity in diabetic patients. Brazil, 2020.

\begin{tabular}{lcccccccccc}
\hline Variables & \multicolumn{2}{c}{ Normal } & \multicolumn{2}{c}{ Mild } & \multicolumn{2}{c}{ Moderate } & \multicolumn{2}{c}{ Severe } & \multicolumn{2}{c}{ Extreme } \\
\cline { 2 - 11 } & $\mathrm{n}$ & $\%$ & $\mathrm{n}$ & $\%$ & $\mathrm{n}$ & $\%$ & $\mathrm{n}$ & $\%$ & $\mathrm{n}$ & $\%$ \\
\hline Stress & 101 & 62.3 & 16 & 9.9 & 18 & 11.1 & 17 & 10.5 & 10 & 6.2 \\
Anxiety & 92 & 56.8 & 14 & 8.6 & 31 & 19.1 & 6 & 3.7 & 19 & 11.7 \\
Depression & 89 & 54.9 & 20 & 12.3 & 20 & 12.3 & 10 & 6.2 & 23 & 14.2 \\
& & & & & & & & & &
\end{tabular}

Table 2

Multivariate analysis of factors associated with signs and symptoms of severe/extreme stress in patients with diabetes during the period of social distancing. Brazil, 2020.

\begin{tabular}{|c|c|c|c|c|c|c|c|c|}
\hline \multirow[t]{2}{*}{ Variables } & \multirow[t]{2}{*}{$\mathbf{N}$} & \multirow[t]{2}{*}{$\%$} & \multicolumn{3}{|c|}{ Initial Model } & \multicolumn{3}{|c|}{ Final Model } \\
\hline & & & OR & $\mathrm{Cl} 95 \%$ & $p$ & OR & $\mathrm{Cl} 95 \%$ & $p$ \\
\hline \multicolumn{9}{|l|}{ Age (years) } \\
\hline$\leq 44$ & 20 & 23.5 & 2.1 & $0.51-8.90$ & 0.29 & & & \\
\hline$>44$ & 7 & 9.1 & 1.0 & & & & & \\
\hline \multicolumn{9}{|l|}{ Female } \\
\hline Yes & 22 & 19.5 & 2.4 & $0.63-8.79$ & 0.20 & & & \\
\hline No & 5 & 10.2 & 1.0 & & & & & \\
\hline \multicolumn{9}{|l|}{ Religion } \\
\hline No & 12 & 36.4 & 5.1 & $1.58-16.40$ & 0.006 & 5.7 & $2.06-15.78$ & $<0.001$ \\
\hline Yes & 15 & 11.6 & 1.0 & & & 1.0 & & \\
\hline \multicolumn{9}{|l|}{ Schooling } \\
\hline Undergraduate & 23 & 23.7 & 2.5 & $0.65-9.43$ & 0.18 & 4.5 & $1.36-14.60$ & 0.01 \\
\hline Post graduate & 4 & 6.2 & 1.0 & & & 1.0 & & \\
\hline \multicolumn{9}{|l|}{ Partner } \\
\hline Yes & 16 & 21.6 & 0.8 & $0.13-5.09$ & 0.82 & & & \\
\hline No & 11 & 12.5 & 1.0 & & & & & \\
\hline \multicolumn{9}{|c|}{ History of anxiety and/ or depression } \\
\hline Yes & 17 & 25.4 & 2.4 & $0.72-8.09$ & 0.15 & & & \\
\hline No & 10 & 10.5 & 1.0 & & & & & \\
\hline \multicolumn{9}{|c|}{ Absence of the children } \\
\hline Yes & 18 & 25.0 & 3.4 & $0.47-23.79$ & 0.22 & & & \\
\hline No & 9 & 10.0 & 1.0 & & & & & \\
\hline
\end{tabular}

Variables excluded from multivariate analysis $(p>0.20)$ : race/color, health area, number of rooms in the residence, monthly income, history of cardiovascular and pulmonary diseases, presence of COVID-19 symptomatology and history of contact with someone suspected or confirmed for COVID-19. 
Análise multivariada dos fatores associados aos sinais e sintomas de estresse grave/extremo em pacientes portadores de diabetes durante o período de distanciamento social. Brasil, 2020.

\begin{tabular}{|c|c|c|c|c|c|c|c|c|}
\hline \multirow[t]{2}{*}{ Variables } & \multirow[t]{2}{*}{$\mathbf{N}$} & \multirow[t]{2}{*}{$\%$} & \multicolumn{3}{|c|}{ Initial Model } & \multicolumn{3}{|c|}{ Final Model } \\
\hline & & & OR & $\mathrm{Cl} 95 \%$ & $p$ & OR & $\mathrm{Cl} 195 \%$ & $p$ \\
\hline \multicolumn{9}{|l|}{ Reduction of work or remote studying } \\
\hline Initiated/ increased/ maintained & 14 & 12.0 & 1.0 & & & & & \\
\hline Reduced/ No & 13 & 28.9 & 2.8 & $0.76-10.27$ & 0.12 & & & \\
\hline \multicolumn{9}{|l|}{ Consumption of alcoholic beverages } \\
\hline Reduced/Do not consume & 21 & 21.6 & 1.0 & & & & & \\
\hline \multicolumn{9}{|l|}{ Practice of physical exercises } \\
\hline Initiated/ increased/ maintained & 6 & 9.2 & 1.0 & & & 1.0 & & \\
\hline Reduced/Do not practice & 21 & 21.6 & 3.7 & $1.01-13.29$ & 0.04 & 3.3 & $1.14-., 83$ & 0.03 \\
\hline \multicolumn{9}{|l|}{ Use of medications for sleeping } \\
\hline Initiated/ increased/ maintained & 17 & 27.4 & 3.1 & $0.89-10.79$ & 0.07 & 3.5 & $1.34-9.17$ & 0.01 \\
\hline \multicolumn{9}{|l|}{ Leisure activities } \\
\hline Initiated/ increased/ maintained & 23 & 15.5 & 1.0 & & & & & \\
\hline Reduced/ Do not have & 4 & 28.6 & 6.5 & $1.14-36.79$ & 0.03 & & & \\
\hline \multicolumn{9}{|l|}{ Social Distancing } \\
\hline Yes & 26 & 18.4 & 7.0 & $0.58-83.79$ & 0.12 & & & \\
\hline No & 1 & 4.8 & 1.0 & & & & & \\
\hline
\end{tabular}

Variables excluded from multivariate analysis $(p>0.20)$ : race/color, health area, number of rooms in the residence, monthly income, history of cardiovascular and pulmonary diseases, presence of COVID-19 symptomatology and history of contact with someone suspected or confirmed for COVID-19.

Table 3

Multivariate analysis of factors associated with signs and symptoms of severe/extreme anxiety in patients with diabetes during the period of social distancing. Brazil, 2020.

\begin{tabular}{|c|c|c|c|c|c|c|c|c|}
\hline \multirow[t]{2}{*}{ Variables } & \multirow[t]{2}{*}{$\mathbf{N}$} & \multirow[t]{2}{*}{$\%$} & \multicolumn{3}{|c|}{ Initial Model } & \multicolumn{3}{|c|}{ Final Model } \\
\hline & & & OR & $\mathrm{Cl} 95 \%$ & $p$ & OR & $\mathrm{Cl} 95 \%$ & $p$ \\
\hline \multicolumn{9}{|l|}{ Age (years) } \\
\hline$\leq 44$ & 18 & 21.2 & 3.0 & $0.73-11.94$ & 0.12 & & & \\
\hline$>44$ & 7 & 9.1 & 1.0 & & & & & \\
\hline \multicolumn{9}{|l|}{ Religion } \\
\hline Yes & 14 & 10.9 & 1.0 & & & 1.0 & & \\
\hline \multicolumn{9}{|l|}{ Schooling } \\
\hline Undergraduate & 20 & 20.6 & 3.6 & $0.69-19.04$ & 0.13 & 5.6 & $1.44-22.00$ & 0.01 \\
\hline Post graduate & 5 & 7.7 & 1.0 & & & 1.0 & & \\
\hline \multicolumn{9}{|l|}{ History of anxiety and/or depression } \\
\hline Yes & 18 & 26.9 & 5.6 & $1.26-24.92$ & 0.02 & 8.6 & $2.54-29.32$ & $<0.001$ \\
\hline \multicolumn{9}{|l|}{ Cardiovascular diseases } \\
\hline Yes & 17 & 19.5 & 3.6 & $0.98-12.98$ & 0.05 & & & \\
\hline No & 8 & 10.7 & 1.0 & & & & & \\
\hline \multicolumn{9}{|l|}{ Reduction of work or remote studying } \\
\hline Initiated/ increased/ maintained & 15 & 12.8 & 1.0 & & & & & \\
\hline Reduced/ No & 10 & 22.2 & 1.0 & $0.24-4.03$ & 0.99 & & & \\
\hline
\end{tabular}

Variables excluded from multivariate analysis $(p>0.20)$ : gender, race/color, health area, presence of partners, number of rooms in the residence, presence of children, history of lung diseases, monthly income, consumption of alcoholic beverages during the pandemic and experiences of social distancing.

continue 
Multivariate analysis of factors associated with signs and symptoms of severe/extreme anxiety in patients with diabetes during the period of social distancing. Brazil, 2020.

\begin{tabular}{|c|c|c|c|c|c|c|c|c|}
\hline \multirow[t]{2}{*}{ Variables } & \multirow[t]{2}{*}{$\mathbf{N}$} & \multirow[t]{2}{*}{$\%$} & \multicolumn{3}{|c|}{ Initial Model } & \multicolumn{3}{|c|}{ Final Model } \\
\hline & & & OR & $\mathrm{Cl} 95 \%$ & $p$ & OR & $\mathrm{Cl} 195 \%$ & $p$ \\
\hline \multicolumn{9}{|l|}{ Practice of physical exercises } \\
\hline Initiated/ increased/ maintained & 5 & 7.7 & 1.0 & & & & & \\
\hline Reduced/Do not practice & 20 & 20.6 & 3.6 & $0.89-14.80$ & 0.07 & & & \\
\hline \multicolumn{9}{|l|}{ Use of medications for sleeping } \\
\hline Reduced/ Do not take any & 9 & 9.0 & 1.0 & & & & & \\
\hline \multicolumn{9}{|c|}{ Absence or reduction of leisure activities } \\
\hline Initiated/ increased/ maintained & 19 & 12.8 & 1.0 & & & 1.0 & & \\
\hline Reduced/Do not have & 6 & 42.9 & 18.7 & $3.05-114.62$ & 0.001 & 16.9 & $3.36-85.15$ & $<0.001$ \\
\hline \multicolumn{9}{|c|}{ Historyof contact with someone suspicious } \\
\hline \multicolumn{9}{|c|}{ for COVID-19 } \\
\hline No & 15 & 12.3 & 1.0 & & & 1.0 & & \\
\hline \multicolumn{9}{|l|}{ Symptoms of COVID-19 } \\
\hline Yes & 5 & 33.3 & 1.6 & $0.30-8.85$ & 0.58 & & & \\
\hline No & 20 & 13.6 & 1.0 & & & & & \\
\hline
\end{tabular}

Variables excluded from multivariate analysis $(p>0.20)$ : gender, race/color, health area, presence of partners, number of rooms in the residence, presence of children, history of lung diseases, monthly income, consumption of alcoholic beverages during the pandemic and experiences of social distancing.

\section{Table 4}

Multivariate analysis of factors associated with signs and symptoms of severe/extreme depression in patients with diabetes during the period of social distancing. Brazil, 2020.

\begin{tabular}{|c|c|c|c|c|c|c|c|c|}
\hline \multirow[t]{2}{*}{ Variables } & \multirow[t]{2}{*}{$\mathbf{N}$} & \multirow[t]{2}{*}{$\%$} & \multicolumn{3}{|c|}{ Initial Model } & \multicolumn{3}{|c|}{ Final Model } \\
\hline & & & OR & C195\% & $p$ & OR & $\mathrm{Cl} 95 \%$ & $p$ \\
\hline \multicolumn{9}{|l|}{ Age (years) } \\
\hline$\leq 44$ & 28 & 32.9 & 2.7 & $0.58-12.81$ & 0.20 & & & \\
\hline$>44$ & 5 & 6.5 & 1.0 & & & & & \\
\hline \multicolumn{9}{|l|}{ Female } \\
\hline Yes & 26 & 23.0 & 3.2 & $0.79-13.06$ & 0.10 & 2.5 & $1.33-4.72$ & 0.004 \\
\hline No & 7 & 14.3 & 1.0 & & & 1.0 & & \\
\hline \multicolumn{9}{|l|}{ Religion } \\
\hline No & 14 & 42.4 & 4.8 & $1.40-16.28$ & 0.01 & 2.2 & $1.34-3.54$ & 0.002 \\
\hline Yes & 19 & 14.7 & 1.0 & & & 1.0 & & \\
\hline \multicolumn{9}{|l|}{ Schooling } \\
\hline Undergraduate & 29 & 29.9 & 3.1 & $0.77-12.26$ & 0.11 & & & \\
\hline Post graduate & 4 & 6.1 & 1.0 & & & & & \\
\hline \multicolumn{9}{|l|}{ Partner } \\
\hline Yes & 25 & 33.8 & 2.0 & $0.29-13.43$ & 0.48 & 4.1 & $2.34-7.13$ & $<0.001$ \\
\hline No & 8 & 9.1 & 1.0 & & & 1.0 & & \\
\hline \multicolumn{9}{|c|}{ Absence of the children } \\
\hline Yes & 27 & 37.5 & 6.1 & $0.82-4 ., 72$ & 0.07 & & & \\
\hline No & 6 & 6.7 & 1.0 & & & & & \\
\hline \multicolumn{9}{|c|}{ Reduction of monthly income } \\
\hline Yes & 19 & 27.1 & 1.7 & $0.50-5.48$ & 0.40 & 1.9 & $1.20-3.11$ & 0.006 \\
\hline No & 14 & 15.2 & 1.0 & & & 1.0 & & \\
\hline
\end{tabular}

Variables excluded from multivariate analysis $(p>0.20)$ : race/color, health area, number of rooms in the residence, history of cardiovascular and pulmonary diseases, performance of leisure activities, presence of COVID-19 symptomatology and history of contact with someone suspicious for COVID-19. 
Multivariate analysis of factors associated with signs and symptoms of severe/extreme depression in patients with diabetes during the period of social distancing. Brazil, 2020.

\begin{tabular}{|c|c|c|c|c|c|c|c|c|}
\hline \multirow[t]{2}{*}{ Variables } & \multirow[t]{2}{*}{$\mathbf{N}$} & \multirow[t]{2}{*}{$\%$} & \multicolumn{3}{|c|}{ Initial Model } & \multicolumn{3}{|c|}{ Final Model } \\
\hline & & & OR & $\mathrm{Cl} 95 \%$ & $p$ & OR & $\mathrm{Cl} 95 \%$ & $p$ \\
\hline \multicolumn{9}{|l|}{ History of anxiety and/or depression } \\
\hline Yes & 22 & 32.8 & 3.1 & $0.94-10.41$ & 0.06 & 2.6 & $1.64-4.14$ & $<0.001$ \\
\hline No & 11 & 11.6 & 1.0 & & & 1.0 & & \\
\hline \multicolumn{9}{|c|}{ Reduction of work or remote studying } \\
\hline Initiated/ increased/ maintained & 19 & 16.2 & 1.0 & & & 1,0 & & \\
\hline Reduced/ No & 14 & 31.1 & 5.0 & $1.17-2 ., 33$ & 0.03 & 1.9 & $1.18-3.11$ & 0.008 \\
\hline \multicolumn{9}{|l|}{ Consumption of alcoholic beverages } \\
\hline Initiated/ increased/ maintained & 10 & 15.4 & 1.3 & $0.36-4.32$ & 0.72 & & & \\
\hline Reduced/ Do not consume & 23 & 23.7 & 1.0 & & & & & \\
\hline \multicolumn{9}{|l|}{ Practice of physical activities } \\
\hline Initiated/ increased/ maintained & 8 & 12.3 & 1.0 & & & & & \\
\hline Reduced/Do not practice & 25 & 25.8 & 3.7 & $1.00-13.36$ & 0.05 & & & \\
\hline \multicolumn{9}{|l|}{ Use of medications for sleeping } \\
\hline Initiated/ increased/ maintained & 18 & 29.0 & 2.5 & $0.71-8.66$ & 0.15 & & & \\
\hline Reduced/Do not take any & 15 & 15.0 & 1.0 & & & & & \\
\hline \multicolumn{9}{|l|}{ Social distancing } \\
\hline Yes & 32 & 22.7 & 7.5 & $0.72-78.06$ & 0.09 & & & \\
\hline No & 1 & 4.8 & 1.0 & & & & & \\
\hline
\end{tabular}

Variables excluded from multivariate analysis $(p>0.20)$ : race/color, health area, number of rooms in the residence, history of cardiovascular and pulmonary diseases, performance of leisure activities, presence of COVID-19 symptomatology and history of contact with someone suspicious for COVID-19.

\section{Discussion}

The frequency of signs and symptoms of stress, anxiety and depression in diabetic patients during the period of social distancing was high, with several factors associated with those disorders.

Within this context, studies relating chronic diseases and the development of mental disorders reveal that diabetes significantly increases the risk of emotional and behavioral disorders, especially in times of social crises such as the one experienced with the COVID-19 pandemic. ${ }^{8}$ This present study corroborates these findings, demonstrating this relation at various levels of intensity, with the frequency of signs and symptoms for anxiety and depression as the most prevalent mental disorders in the sample studied.

Regarding the negative outcomes of the pandemic involving mental health, studies have shown that women are more vulnerable to stress, anxiety, depression, physical symptoms and impairment of social functioning. 11,12 The results of this study also show a higher frequency of depression in diabetic women. This phenomenon can result from multiple determinants, from estrogen hormone levels, which have an influence on emotional lability, to sociocultural context. 13,14

Diabetes, for being a multi-systemic disease, needs a broad and plural approach, both in relation to drug treatments and mental health. 15 The search for this psychological well-being has become a reason for studies by the scientific community, so that the presence of religiosity, in addition to cultural factors in the lives of diabetic individuals has been considered a protective factor for the progression of the disease, helping to face problems and increasing the feeling of social belonging, ${ }^{15}$ which was observed in our study.

Compared to periods of normality, loneliness and the need for companionship intensified during social distancing, ${ }^{16}$ especially in individuals with a history of contact with someone suspected for COVID-19. These feelings are considered of common concerns in diabetics, as well as the excessive anxiety of being infected, the risk group label and the consideration of being unable to control diabetes if infected by COVID-19.16 These factors narrow the relationship with psychosocial outcomes, as seen by the depressive symptomatology in those who did not have a companion and anxiety symptomatology in those with previous contact with COVID-19. 
Economic stasis is considered one of the main consequences of the COVID-19 pandemic, as well as an important precursor of psychological disorders and, in the long run, of alcohol and other drug abuse. ${ }^{17}$ The association of monthly income reduction and the observed appearance of depressive symptoms demonstrates that these patients are significantly affected by financial destruction, since they have onerous therapeutic schemes involving multiple professionals. ${ }^{3}$

The need to adhere to social restriction measures, such as the removal of family members and friends, work changes and limitations of leisure activities and physical exercise practices, has implied changes in the daily routine and lifestyle of the individuals, which, in a certain way, may cause impacts on the mental health of those involved, especially diabetics. 18 In this group in particular, the restriction on the practice of physical activities takes on a prominent dimension, since sedentariness constitutes an important disease factor in the prognosis, especially for type 2 diabetics, since these patients often have associated metabolic and endocrine comorbidities. 19,20

Because it is a prevalent disease, current research is seeking to identify factors that may be associated with diabetes. ${ }^{21}$ Among these factors, the presence of historical anxiety and/or depression stands out, which besides being precursors for diabetes, are also involved in the emergence of coronary diseases and the recurrence of psychopathologies. 21 These data were ratified by the current study. The permanence, onset or increased use of sleeping medications during the pandemic was considered a risk association for signs and symptoms of severe/extreme stress. This result comes from the association between the presence of sleep disorders and a decrease in the quality of life of the individuals, which generates an increase in stress events, especially in diabetic patients. 22

It should also be noted that in addition to the beneficial effects being limited, the increase in selfprescription of these medications can culminate in psychopathologies with more severe symptoms. ${ }^{22}$

The limitations of daily activities had as an alternative the application of remote methodologies and, although they supply the needs and become a parallel form of socialization, this conduct is seen as very stressful, besides contributing to the feeling of boredom and idleness, 23 exacerbating sadness and depressive symptoms. ${ }^{23}$ This association is more frequent in individuals who do not have work or study remotely, as found in the present study. The stress that comes from virtual dynamics has mainly affected college students, who have a stressful routine due to intense workload, extracurricular activities and social pressure facing the professional future. 24

Our study highlights attention to undergraduate students with diabetes, since stress can alter insulin levels, contributing to anxious symptoms and worsening prognosis. 25

This study did not address specific issues for the diabetic patient such as the type and severity of the disease, presence of comorbidities, the treatment in use and about the time and forms of diagnosis. Another important point was due to the study design being a cross-sectional section, it was not possible to determine the causal relation between diabetes mellitus and psychic symptoms. Thus, it is suggested to carry out new research to analyze these aspects and with different study designs.

Studies performed by digital means present sampling limitations. The disclosure through an online form, allows the inclusion of a diverse population, however, because of the contacts of researchers, the sample was limited, even requesting disclosure by all, in an attempt to achieve maximum coverage. It should be noted that the calculated sample size was reached. Also, it is likely that the less favored population was not contemplated due to the restrictions to access the digital platforms, and the difficulty of understanding some issues online form, leading to doubts, but this aspect was minimized with the dissemination of the researchers' telephone contacts.

Thus, it is suggested that new research with a larger sample number, covering a more diverse population, such as the less favored and patients from of the Public Health System (SUS), should be conducted.

It is concluded, then, that afrequency of signs and symptoms for stress, anxiety and depression in people with diabetes mellitus suffered a slight increase when compared to studies conducted in periods prior to social distancing in the same population of diabetics. Furthermore, it was observed that these psychopathologies were associated with several factors related to the period of social restriction experienced today, highlighting the decrease in income, the practice of leisure activities and physical exercises and the history of contact with suspicion for COVID-19 as the main ones. Therefore, it is recommended the creation of care strategies focused on the mental health of these individuals, such as the availability of digital content that encourages the practice of leisure and physical exercise, as well as training courses to encourage entrepreneurship. 


\section{Authors' contribution}

Conception and design of the research: Souza GFA, Praciano GAF, Neto OCF, Paiva MC, Jesus RPFS, Junior JRS, Santos AC and Souza ASR; Data collection: Souza GFA, Praciano GAF, Cordeiro ALN, Junior JRS and Souza ASR; Data analysis and interpretation and manuscript writing: Souza GFA, Praciano GAF, Neto OCF, Paiva MC, Jesus RPFS, Junior JRS, Santos AC and Souza ASR; Statistical

\section{References}

1. Tripathi BK, Srivastava AK. Diabetes mellitus: complications and therapeutics. Medical Sci Monit. 2006; 12 (7): 130-47.

2. Federação internacional de Diabetes. Diabetes facts and figures. Pernambuco; 2020, [acesso 28 agosto 2020]. Disponível em: https://www.idf.org/aboutdiabetes/what-isdiabetes/facts-figures.html.

3. Khalighi Z, Badfar G, Mahmoudi L, Soleymani A, Azami M, Shohani M. The prevalence of depression and anxiety in Iranian patients with diabetes mellitus: a systematic review and meta-analysis. Diabetes Metab Syndr. 2019; 13 (4): 2785-94.

4. Keskin A, Bllge U. Mental disorders frequency alternative and complementary medicine usage among patients with hypertension and type 2 diabetes mellitus. Niger J Clin Pract. 2014; 17 (6):717-22.

5. Amiri S, Behnezhad S. Obesity and anxiety symptoms: a systematic review and meta-analysis. Neuropsychiatr. 2019; 33 (2):72-89.

6. Whitworth SR, Bruce DG, Starkstein SE, Davis WA, Davis TME, Bucks RS. Lifetime depression and anxiety increase prevalent psychological symptoms and worsen glycemic control in type 2 diabetes: the Fremantle Diabetes Study Phase II. Diabetes Res Clin Pract. 2016; 122: 190-7.

7. CDC (Centers for Disease Control and Prevention). People who are at higher risk for severe illness. Content source: National Center for Immunization and Respiratory Diseases (NCIRD), Division of Viral Diseases. 2020. [acesso 6 Set 2020] Disponível em: https://www.cdc.gov/coronavirus/2019-ncov/need-extra-

precautions/index.html?CDC_AA_refVal=https $\% 3 \mathrm{~A} \% 2 \mathrm{~F} \%$ 2 Fwww.cdc.gov $\% 2$ Fcoronavirus $\% 2$ F2019-ncov $\% 2$ Fneedextra-precautions $\% 2$ Fpeople-at-increased-risk.html.

8. Alessi J, Oliveira GB, Franco DW, Amaral BB, Becker AS, Knijnik CP, Telo GH. Mental health in the era of COVID19: prevalence of psychiatric disorders in a cohort of patients with type 1 and type 2 diabetes during the social distancing. Diabetol Metab Syndr. 2020; 12 (76): 1-10.

9. Minayo MCS. O desafio do conhecimento: pesquisa qualitativa em saúde. 13. Ed., São Paulo: Hucitec; 2013.

10. Vignola RCB, Tucci AM. Adaptation and validation of the depression, anxiety and stress scale (DASS) to Brazilian Portuguese. J Affect Disord. 2014; 155: 104-9. analysis: Souza GFA and Souza ASR; Critical review of the manuscript regarding important intellectual content: Souza GFA, Praciano GAF, Neto OCF, Paiva MC, Jesus RPFS, Junior JRS, Santos AC and Souza ASR. All authors approved the final version of the article.

11. Solomou I, Constantinidou F. Prevalence and predictors of anxiety and depression symptoms during the COVID-19 pandemic and compliance with precautionary measures: age and sex matter. Int J Environ Res Public Health. 2020; 17 (14): 4924

12. Qiu J, Shen B, Zhao M, Wang Z, Xie B, Xu Y. A nationwide survey of psychological distress among Chinese people in the COVID-19 epidemic: implications and policy recommendations. Gen Psychiatr. 2020; 33 (2): 1-3.

13. Hantsoo L, Epperson CN. Anxiety disorders among women: a female lifespan approach. Focus. 2017; 15(2), 162-72.

14. Wang C, Pan R, Wan X, Tan Y, Xu L, Ho CS, Ho RC. Immediate psychological responses and associated factors during the initial stage of the 2019 coronavirus disease (COVID-19) epidemic among the general population in China. Int J Environ Res Public Health. 2020; 17: 17-29.

15. Permana I, Ormandy P, Ahmed A. Maintaining harmony: how religion and culture are interwoven in managing daily diabetes self-care. J Relig Health. 2019; 58: 1415-28.

16. Joensen LE, Madsen KP, Holm L, Nielsen KA, Rod MH, Petersen AA, Willaing I. Diabetes and COVID $\square$ 19: psychosocial consequences of the COVID $\square 19$ pandemic in people with diabetes in Denmark - what characterizes people with high levels of COVID $\square 19 \square$ related worries? Diabet Med. 2020; 37 (7): 1146-54.

17. Crayne MP. The traumatic impact of job loss and job search in the aftermath of COVID-19. Psychol Trauma. 2020; 12 (1): $180-2$.

18. Ruiz-Roso MB, Knott-Torcal C, Matilla-Escalante DC, Garcimartín A, Sampedro-Nuñez MA, Dávalos A, Marazuela M. Covid-19 lockdown and changes of the dietary pattern and physical activity habits in a cohort of patients with type 2 diabetes mellitus. Nutrients. 2020; 12 (8): 23-7.

19. Jiménez-Pavón D, Carbonell-Baeza A, Lavie CJ. Physical exercise as therapy to fight against the mental and physical consequences of Covid-19 quarantine: special focus in older people. Prog Cardiovasc Dis. 2020; 63 (3): 386-8.

20. Gupta S, Tang C, Higgs P. Social isolation during Covid19: Boon or bane to diabetes management. Diabet Metab Syndr. 2020; 14 (4): 567-8. 
21. Hung MY, Mao CT, Hung MJ, Wang JK, Lee HC, Yeh CT, $\mathrm{Hu}$ P, Chen TH, Chang NC. Coronary artery spasm as related to anxiety and depression: a nationwide populationbased study. Psychosom Med. 2019; 81 (3): 237-45.

22. Votaw VR, Geyer R, Rieselbach MM, McHugh RK. The epidemiology of benzodiazepine misuse: A systematic review. Drug Alcohol Depend. 2019; 200: 95-114.

23. Droit-Volet S, Gil S, Martinelli N, Andant N, Clinchamps M, Parreira L, Rouffiac K, Dambrun M, Huguet P, Dubuis B, Pereira B. Time and Covid-19 stress in the lockdown situation: Time free, «Dying» of boredom and sadness. PloSone. 2020; 15 (8): 0236465.

Received on September 25, 2020

Approved on October 13, 2020
24. Lima RC. Distanciamento e isolamento sociais pela Covid19 no Brasil: impactos na saúde mental. Physis (Rio J.). 2020; 30 (2): 1-10.

25. Mesquita AA, Lobato JL, de Almada Lima VFS, Brito KP. Estresse, enfrentamento e sua influência sobre a glicemia e a pressão arterial. Rev Psicol Saúde. 2014; 6 (1): 48-55. 